\title{
Elevated Risk of COVID-19 Infection for Hospital-Based Health Care Providers
}

J Gen Intern Med 36(11):3642-3

DOI: $10.1007 / \mathrm{s} 11606-021-07088-7$

(C) Society of General Internal Medicine 2021

\section{INTRODUCTION}

There have been numerous reports of SARS-CoV-2 infection among health care workers (HCWs) across the globe. However, data is lacking on risk of hospital vs. community COVID-19 exposure faced by US providers. We report COVID-19 infection rates for physicians (MDs) and advance practice providers (APPs) in hospital medicine and critical care at a national acute care medical practice between March and December 2020.

\section{METHODS}

\section{Setting and Subjects}

Data for this study comes from a national medical group specializing in hospital medicine (HM), critical care (CCM), and emergency medicine. At most of the 200 community hospitals in 41 states staffed by the group, these staff are the only hospital medicine providers. It serves hospitals in states that were impacted by the early COVID-19 surge, including Washington, Michigan, Ohio, and New York. Human Resources collects daily data regarding COVID-19 testing on all payroll employees. Local hospital testing (with an FDAapproved RT-PCR test) is triggered by symptoms or exposure to an infected person without personal protective equipment (PPE).

We assembled daily cumulative counts of COVID-19 testpositive providers with at least 100 patient contacts MarchDecember 2020. The number of COVID-19 patients in each hospital overall was used as a proxy for community COVID19 exposure. We included data from the National Neighborhood Data Archive (NaNDA): Socioeconomic Status and Demographic Characteristics of ZIP Code Tabulation Areas, USA, 2008-2017 to control for demographics that could influence hospitalization.

The work was performed at The Dartmouth Institute.

Received March 25, 2021

Accepted July 28, 2021

Published online August 17, 2021

\section{Analysis}

We calculated cumulative provider infection rates overall, by provider type (APP or MD) and by specialty (HM or CCM). We used mixed-effects logistic regression with hospital treated as a random effect to explore the relationship between provider infection, characteristics of the providers, and the number of COVID-19 patients at the hospital and treated by the providers. In sensitivity analysis, we tested a hospital fixed effects model to obtain estimates of the within hospital effects of provider-specific exposure to COVID-19 patients. Since the point estimates were similar from both models, we report results of the mixed effects model.

\section{RESULTS}

This analysis includes $3108 \mathrm{~W} 2$ employed providers with at least 100 patient contacts March-December 2020. A total of 180 providers were tested; 88 were positive, 90 negative, and 2 pending. The provider cumulative infection rate was $2.8 \%$, $2.3 \%$ for MDs and $3.9 \%$ for APPs $(p=0.069)$. There were no statistically significant differences in provider infection by specialty (HM 2.6\%, CCM 2.1\%; $p=0.644$ ) (Table 1). The infection rate increased by the number of COVID-19 patients under direct care of the providers. The infection rate was $0.9 \%$ for providers who took care of $<10$ COVID-19 patients, $2.4 \%$ for providers caring for 10-49 COVID-19 patients (OR 2.7, 95\%CI $1.1-6.8, \mathrm{p}=0.037$ ), and $4.1 \%$ for providers caring for $50+$ COVID-19 patients (OR 4.8, 95\%CI 1.8-12.9, $\mathrm{p}=0.002$ ). The number of hospital COVID-19 patients was not associated with provider COVID-19 infections $(<150$ COVID-19 patients $=2.7 \%$ provider positive rate; $150-500$ COVID-19 patients $=2.1 \%$ provider positive rate $[\mathrm{OR} 0.8,95 \% \mathrm{CI} 0.3-1.8$, $\mathrm{p}=0.532] ;>500$ COVID-19 patients $=2.9 \%$ provider positive rate [OR 1.1, 95\%CI 0.4-2.7, $\mathrm{p}=0.851]$ ).

\section{DISCUSSION}

In this nationwide study of infection risk among 3108 hospital-based providers, staff caring for larger numbers of COVID-19 patients were at elevated risk for COVID-19 infection. The number of COVID-19 patients treated at each hospital was not associated with increased risk of infection. These findings suggest that it is not the total number of COVID-19 patients hospitalized, which may reflect the 
Table 1 Relationship Between Provider Characteristics and Patient Volumes and COVID-19 Infection

\begin{tabular}{|c|c|c|c|c|c|}
\hline \multirow[t]{2}{*}{ Variable } & \multirow{2}{*}{$\begin{array}{l}\text { Infection } \\
\text { rate }\end{array}$} & \multicolumn{4}{|c|}{$95 \%$ confidence interval } \\
\hline & & $\begin{array}{l}\text { Odds } \\
\text { ratio }\end{array}$ & $\begin{array}{l}\text { Lower } \\
\text { bound }\end{array}$ & $\begin{array}{l}\text { Upper } \\
\text { bound }\end{array}$ & $\begin{array}{l}p \text { - } \\
\text { value }\end{array}$ \\
\hline \multicolumn{6}{|c|}{ Provider COVID-19 contacts } \\
\hline$<10$ & $\begin{array}{l}3976 \\
(0.9 \%)\end{array}$ & & & & \\
\hline $10-49$ & $\begin{array}{l}2104 \\
(2.4 \%)\end{array}$ & 2.7 & 1.1 & 6.8 & 0.037 \\
\hline $50+$ & $\begin{array}{l}1729 \\
(4.1 \%)\end{array}$ & 4.8 & 1.8 & 12.9 & 0.002 \\
\hline \multicolumn{6}{|c|}{ Hospital COVID-19 contacts } \\
\hline$<150$ & $\begin{array}{l}2633 \\
(2.3 \%)\end{array}$ & & & & \\
\hline $150-500$ & $\begin{array}{l}2498 \\
(2.1 \%)\end{array}$ & 0.8 & 0.3 & 1.8 & 0.532 \\
\hline$>500$ & $\begin{array}{l}2678 \\
(2.9 \%)\end{array}$ & 1.1 & 0.4 & 2.7 & 0.861 \\
\hline \multicolumn{6}{|c|}{ Provider type } \\
\hline MD & $\begin{array}{l}6730 \\
(2.3 \%)\end{array}$ & & & & \\
\hline APP & $\begin{array}{l}1079 \\
(3.9 \%)\end{array}$ & 1.8 & 1.0 & 3.3 & 0.069 \\
\hline \multicolumn{6}{|l|}{ Service } \\
\hline $\begin{array}{l}\text { Hospital } \\
\text { medicine }\end{array}$ & $\begin{array}{l}7134 \\
(2.6 \%)\end{array}$ & & & & \\
\hline $\begin{array}{l}\text { Critical } \\
\text { care }\end{array}$ & $\begin{array}{l}675 \\
(1.9 \%)\end{array}$ & 0.8 & 0.3 & 2.1 & 0.644 \\
\hline
\end{tabular}

number of COVID-19 patients in that hospital's community, but the number of COVID-19 patients that providers directly treat which increases the risk of virus transmission.

There is mixed evidence on provider transmission. Some suggest infections arise from the hospital and community, ${ }^{1}$ some have pointed to community-acquired infection, ${ }^{2,3}$ and others have shown higher in hospital transmission. ${ }^{4-6}$ In these studies, HCWs do tend toward higher seropositivity rate than people in the community.

Our study is limited by the approximation we used to estimate provider infection, as well as the fact that we could not measure provider incidence of infection over time. Overall, in our large nationwide study of provider infection risk, the number of COVID-19 patients treated was associated with increased provider infections. Given the possibility of increased risk of transmission, continued vigilance factors highly in protecting providers from occupational risk for COVID19.

Acknowledgements: We acknowledge contributions of Kristi Franz, Jocelyn Ludwick, Anoop Nanda, and Megan Murphy for research assistance. The potential conflicts of interest include that John Birkmeyer and Annie Fowler have equity interest as officers for Sound Physicians. Nancy Birkmeyer is married to John Birkmeyer.
Olivia A. Sacks, $M D^{1}$

Amber E. Barnato, MD, MPH, $M S^{2}$

Jonathan S. Skinner, $\mathrm{Ph} \mathrm{D}^{2,3}$

John D. Birkmeyer, $M D^{4}$

Annie Fowler, $M B A^{4}$

Nancy Birkmeyer, $\mathrm{PhD}^{2}$

${ }^{1}$ Department of Surgery, Boston Medical Center, Boston, MA, USA

${ }^{2}$ The Dartmouth Institute for Health Policy and Clinical Practice, Geisel School of Medicine at Dartmouth,

Lebanon, NH, USA

${ }^{3}$ Department of Economics, Dartmouth College,

Hanover, NH, USA

${ }^{4}$ Sound Physicians,

Tacoma, WA, USA

Corresponding Author: Olivia A. Sacks, MD; Department of Surgery, Boston Medical Center, Boston, MA, USA (e-mail: Olivia.Sacks@bmc.org).

Funding P01 AG019783

Declarations:

Conflict of Interest: This work was funded by a research grant awarded to Dartmouth College by the National Institute on Aging (P01 AG019783)

\section{REFERENCES}

1. Lai X, Wang M, Qin C, et al. Coronavirus Disease 2019 (COVID-2019) Infection Among Health Care Workers and Implications for Prevention Measures in a Tertiary Hospital in Wuhan, China AMA Netw Open 2020;3:e209666.

2. Sikkema RS, Pas SD, Nieuwenhuijse DF, et al. COVID-19 in health-care workers in three hospitals in the south of the Netherlands: a crosssectional study. Lancet Infect Dis 2020.

3. Kluytmans-van den Bergh MFQ, Buiting AGM, Pas SD, et al. Prevalence and Clinical Presentation of Health Care Workers With Symptoms of Coronavirus Disease 2019 in 2 Dutch Hospitals During an Early Phase of the Pandemic. JAMA Netw Open 2020;3:e209673.

4. Murakami E, Ghatak-Roy A, Popova M, et al. COVID-19 infection among emergency department healthcare providers in a large tertiary academic medical center following the peak of the pandemic. Am J Emerg Med 2021;40:27-31.

5. Iversen K, Bundgaard H, Hasselbalch RB, et al. Risk of COVID-19 in health-care workers in Denmark: an observational cohort study. The Lancet Infectious diseases 2020;20:1401-8.

6. Nguyen LH, Drew DA, Joshi AD, et al. Risk of COVID-19 among frontline healthcare workers and the general community: a prospective cohort study. medRxiv 2020.

Publisher's Note: Springer Nature remains neutral with regard to jurisdictional claims in published maps and institutional affiliations. 